\title{
OCORRÊNCIAS DE ALAGAMENTOS, ENXURRADAS E INUNDAÇÕES E A VARIABILIDADE PLUVIOMÉTRICA NA BACIA HIDROGRÁFICA DO RIO IGUAÇU
}

\author{
CALDANA, Nathan Felipe da Silva - nathancaldana@gmail.com \\ Universidade Tecnológica Federal do Paraná / UTFPR \\ YADA JUNIOR, George Mitsuo - geoyada@gmail.com \\ Instituto Agronômico do Paraná / IAPAR
MOURA, Denis Anderson Vieira de - denis.avieiram@gmail.com Universidade Estadual de Londrina / UEL
COSTA, Angela Beatriz Ferreira da - angelabcosta@gmail.com Instituto Agronômico do Paraná / IAPAR
CARAMORI, Paulo Henrique - pcaramori@gmail.com Instituto Agronômico do Paraná / IAPAR

\begin{abstract}
RESUMO: As condições de tempo e clima são essenciais para a agricultura e o desenvolvimento da sociedade, entretanto, sua dinâmica pouco compreendida pode comprometer algumas atividades humanas. Estudos a respeito da variabilidade da precipitação são fundamentais para o planejamento e tomada de decisão para atividades agrícolas e atividades urbanas. A Região Metropolitana de Curitiba (RMC) possui um grande contingente populacional com grande vulnerabilidade a eventos climáticos extremos, além disso, o médio e baixo Iguaçu são importantes áreas agrícolas do estado, sendo necessários estudos que auxiliem para o planejamento na região. Dessa forma, objetivou-se analisar a variabilidade pluviométrica mensal, sazonal e anual e a distribuição das ocorrências de alagamentos, enxurradas e inundações na bacia hidrográfica do Rio Iguaçu. O recorte temporal utilizado para a análise climática foi de 1977 a 2017. Utilizou-se dados de 78 estações meteorológicas ou pluviométricas distribuídas na área da bacia, além de dados por município de ocorrência de alagamentos, enxurradas ou inundações. Para a análise da precipitação utilizou-se mapa de isoietas e a estatística do box plot e para espacialização das ocorrências dos desastres, foram criados mapas temáticos. Identificou-se grande variabilidade regional, anual, sazonal e mensal da precipitação na bacia. Ocorreram 861 casos de alagamentos, enxurradas ou inundações com 872 mil pessoas afetadas em 18 anos de análise.
\end{abstract}

PALAVRAS-CHAVE: vulnerabilidade, risco climático, eventos extremos.

OCCURRENCES OF FLOODING, RUNOFF AND INUNDATION, AND THE PLUVIOMETRIC VARIABILITY IN THE HYDROGRAPHIC BASIN OF THE IGUAÇU RIVER

ABSTRACT: The conditions of weather and climate are essential for agriculture and the development of society; however, their little understood dynamics can compromise some human activities. Studies on precipitation variability are critical for planning and decision making for agricultural activities and urban activities. The Metropolitan Region of Curitiba (RMC) has a large population contingent with great vulnerability to extreme climatic events; in addition, the medium and low Iguaçu are important agricultural areas of the state, and studies are needed to assist planning in the region. The objective of this study was to analyze the monthly, seasonal and annual rainfall variability and the distribution of occurrences of floods, inundation and runoff in the Iguaçu River basin. The period used for the climatic analysis was from 1977 to 2017. Data from 78 meteorological or pluviometric stations distributed in the basin area were used, as well as data by municipality of occurrence of floods, inundation or runoff. For the analysis of the 
precipitation was used isohyets mapping and the statistic of the box plot, and for spatialization of the occurrences of the disasters were created thematic maps. It was identified great regional, annual, seasonal and monthly variability of the precipitation in the basin. There were 861 cases of floods, inundation or runoff, with 872,000 people affected in 18 years of analysis.

KEYWORDS: vulnerability, climatic risk, extreme events.

\section{INTRODUÇÃO}

A variabilidade climática é um "produto tanto do espaço quanto do tempo" (CONTI, 2005). O seu ritmo não é igual de um ano para o outro e nem de década para década. As flutuações variam em curto, médio e longo prazo e, neste caso, o clima é resultado de um processo complexo que envolve a radiação solar, atmosfera, oceano, superfícies sólidas, neve, gelo, etc. (KARIMI et al. 2017; PAILLER e TSANEVA, 2018; SOMBOONSUKE et al. 2018).

Dessa maneira, a variabilidade climática exerce uma influência significativa sobre as atividades humanas, pois pode causar oscilações de temperatura, precipitação e frequência de eventos extremos como secas e chuvas intensas, resultando em impactos na agricultura, nos recursos hídricos, na saúde e sobre o meio ambiente em escala local ou regional. As respostas dos ciclos energéticos e hidrológicos sobre a superfície têm um papel crítico na determinação dos impactos da variabilidade e mudanças climáticas sobre o espaço. A variabilidade climática pode, inicialmente, modificar os recursos hídricos locais e o albedo da superfície, de forma que o processo pode provocar pequenas ou até grandes modificações na temperatura, precipitação e evaporação, entre outros parâmetros meteorológicos (SILVA e SILVA, 2012; LÓPEZ, 2018; WOSSEN, 2018).

A agricultura, principalmente a produção de grãos e a pecuária extensiva, compõem a base da atividade econômica da Região Sul do Brasil. Para a agropecuária os estudos da variabilidade climática se fazem necessário, uma vez que interfere diretamente no tipo de cultura a ser produzida em determinada região, sua época de plantio, no uso de agroquímicos e no tipo de irrigação a ser utilizada, além de principalmente, ter papel decisivo na variabilidade da produção. Trabalhos que identifiquem e prevejam períodos de seca, chuva intensa, vendavais e geadas contribuem para um melhor planejamento, manejo de culturas e tomada de decisões, visando uma melhor forma de se obter bons resultados com essa modalidade econômica (BERLATO e FONTANA, 2003; AGOVINO et al., 2018; KARIMI et al., 2018; LUNGARSKA e CHAKIR, 2018; PATHMESWARAN et al., 2018; WIRÉHN, 2018).

Desastres naturais, como consequência de episódios extremos de precipitação, são definidos como fenômenos da natureza que transformam a paisagem e o espaço geográfico. Caso estes se intensifiquem no meio social podem gerar situações de perigo, ocasionando óbitos e danos materiais com prejuízos de difícil reparo. Os casos de inundação, enxurradas e alagamentos são os mais comuns dentre os eventos hidroclimatológicos. Conforme Marcelino (2007) a inundação é a principal consequência dos eventos extremos do clima, com $59 \%$ dos registros. Tais eventos ocorrem em mais de $80 \%$ das cidades brasileiras e estão associados às instabilidades atmosféricas severas.

Os alagamentos estão associados a processos de acúmulo de água em determinados locais, principalmente em baixadas, por ineficiência no sistema de 
drenagem. Já as inundações associadas a precipitação, são causadas, principalmente pela falta de drenagem, e ocorrem com o transbordamento de um curso hídrico sobre sua área de várzea (muitas vezes ocupadas por construções humanas). Enquanto as enxurradas ocorrem em processo similar a inundação, porém com maior área de abrangência e alto poder de transporte. Suas incidências em espaços ocupados e habitados pelo homem causam sérios danos, muitas vezes irreparáveis. Esses eventos podem se intensificar com os cenários de mudanças climáticas e serem ainda mais danosos em conjunto às constantes mudanças no uso e ocupação do solo sem planejamento (MARCELINO, 2007; HAMMOND et al., 2015 TANAKA et al. 2017; CHEN et al. 2018; JAMALI et al. 2018).

Estudos climáticos são fundamentais para o planejamento das atividades humanas no Estado do Paraná, visto que este se localiza em área de transição climática, com grandes oscilações de temperatura e precipitação devido aos fatores latitudinal, longitudinal e de altitude (CARAMORI et al., 2001). Dessa forma, objetivou-se analisar a variabilidade pluviométrica mensal, sazonal e anual e a distribuição das ocorrências de alagamento, enxurradas e inundações na bacia hidrográfica do Rio Iguaçu. O recorte temporal utilizado para a análise climática foi de 1977 a 2017.

\section{MATERIAIS E MÉTODOS}

Foram utilizados dados de 76 estações pluviométricas do Instituto Agronômico do Paraná (IAPAR), Instituto Nacional de Meteorologia (INMET), Agência Nacional das Águas (ANA) e do Instituto das Águas do Paraná. As estações estão distribuídas dentro da área da bacia ou em municípios com parte de sua área total localizada na bacia (Figura 01).

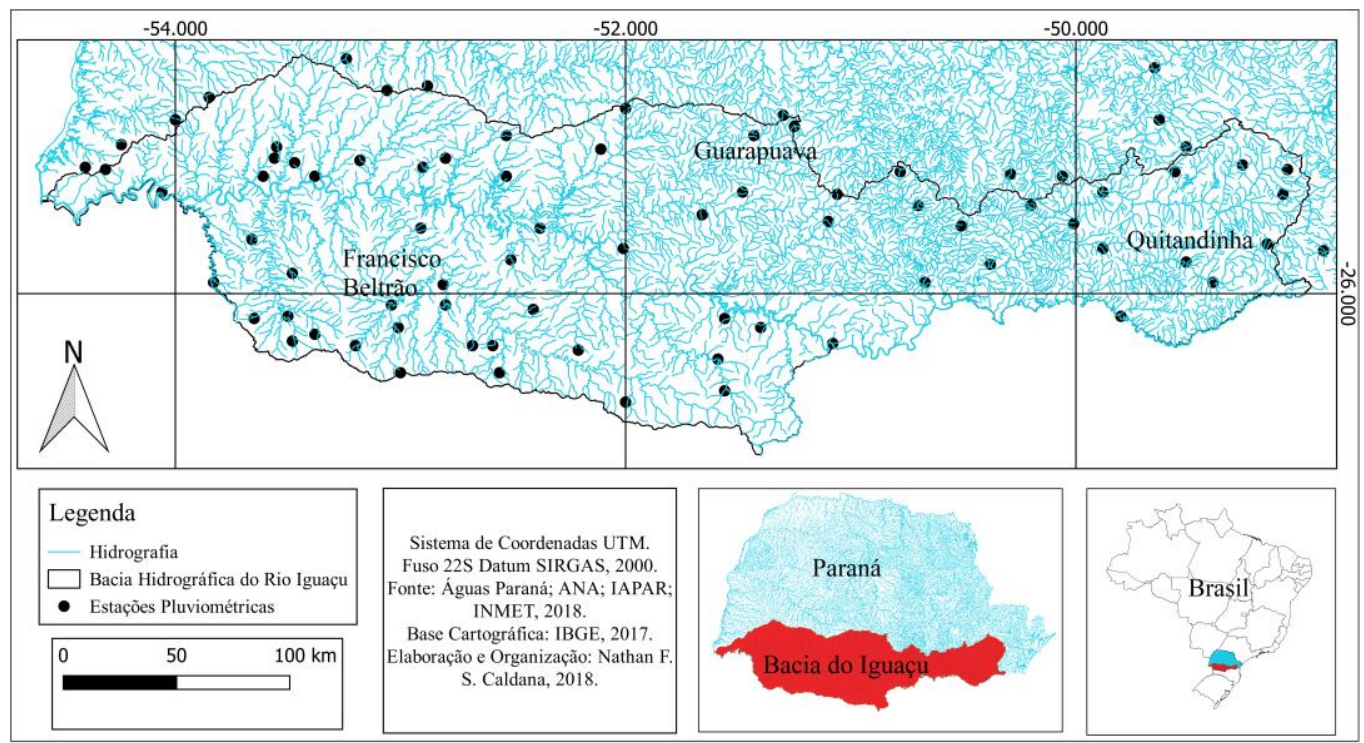

Figura 1 - Localização da área de estudo e das estações pluviométricas. 
A espacialização dos dados pluviométricos médios da bacia foi representada por meio de isoietas, utilizando o algoritmo de interpolação espacial Inverse distance weighted (IDW). A principal vantagem desse método é a representação espacial dos dados de chuvas (MUELLER et al. 2004). Os mapas foram criados por meio do Software Qgis.

Para complementar a análise da variabilidade pluviométrica, foram utilizados os gráficos de box plot ou diagrama de caixa. O principal recurso obtido em sua utilização é "fornecer uma visualização rápida da distribuição dos dados. Se a distribuição é simétrica a caixa encontra-se equilibrada com a mediana se posicionando no centro da mesma. Já para distribuições assimétricas, há um desequilíbrio na caixa, com relação à mediana" (SILVESTRE et al., 2013, p. 27).

Os box plots são trabalhados por cinco classificações de valores. Os outliers são divididos em discrepantes (valores acima do considerado máximo, mas que não são extremos) e extremos, sendo considerados qualquer valor superior a Q3 + 1,5 (Q3 - Q1) ou inferior a Q1 - 1,5 (Q3 - Q1). Os máximos e mínimos são considerados os maiores valores da série, mas que não são extremos ou discrepantes. Dentro da caixa são classificados três quartis com $25 \%$ dos dados cada, além do valor da mediana, equivalente ao segundo quartil, ou 50\% dos dados (LEM et al., 2013; SCHNEIDER e DA SILVA, 2014).

Para a análise por meio de box plot foram utilizadas três estações meteorológicas. O parâmetro para a escolha das estações pautou-se na subdivisão pré-estabelecida da bacia (Alto, Médio e Baixo Iguaçu), sendo estas, Francisco Beltrão (Baixo Iguaçu), Guarapuava (Médio Iguaçu) e Rio Várzea dos Lima - Quitandinha (Alto Iguaçu).

Para a identificação das ocorrências de alagamentos, enxurradas e inundações, foram utilizados dados da Defesa Civil do Paraná. A Proteção Civil Brasileira age de acordo com a necessidade da emergência e de serviço a ser prestado por assistência às populações afetadas. A ação é imediata após o desastre e as equipes enviadas para o campo são responsáveis por realizar o preenchimento de um relatório descrevendo o fenômeno e os danos resultantes (MARTINS et al., 2017, p. 127). A Defesa Civil do Paraná é estruturada por oito Coordenadorias Regionais de Defesa Civil, sendo que cada município possui sua Coordenadoria Municipal de Defesa Civil. A obtenção dos dados foi feita na Coordenadoria Estadual de Proteção e Defesa Civil do Paraná por meio dos Relatórios de Ocorrência de alagamento, enxurrada e inundação. Os dados coletados foram números de ocorrências, pessoas afetadas e óbitos.

\section{RESULTADOS}

A precipitação média na bacia hidrográfica do Rio Iguaçu (Figura 02) apresenta grande diferença regional. Enquanto a região do médio e baixo Iguaçu apresentam valores de 1900 a 2200mm, em média, a região do alto Iguaçu apresenta valores de 1410 a 1900mm.

Três fatores são essenciais para justificar essa discrepância nos valores da precipitação média na bacia. Primeiramente, a diferença de altitude, uma vez que, o Rio Iguaçu nasce a cerca de $1000 \mathrm{~m}$ na região de Pinhais e desagua em Foz do Iguaçu, com altitude de $100 \mathrm{~m}$. Essa grande diferença altimétrica atrelada 
à maritimidade e a entrada das frentes frias pelas calhas do Rio Paraná e posteriormente do Iguaçu, contribuem para maiores alturas pluviométricas na região oeste da bacia. Outro fator de grande importância na variabilidade pluviométrica, que influencia de forma diferente as chuvas da bacia é o fenômeno El Niño-Oscilação Sul - ENOS (ROCHA e SANT'ANNA NETO, 2010; CALDANA e ELY, 2016; PINHEIRO, 2016).

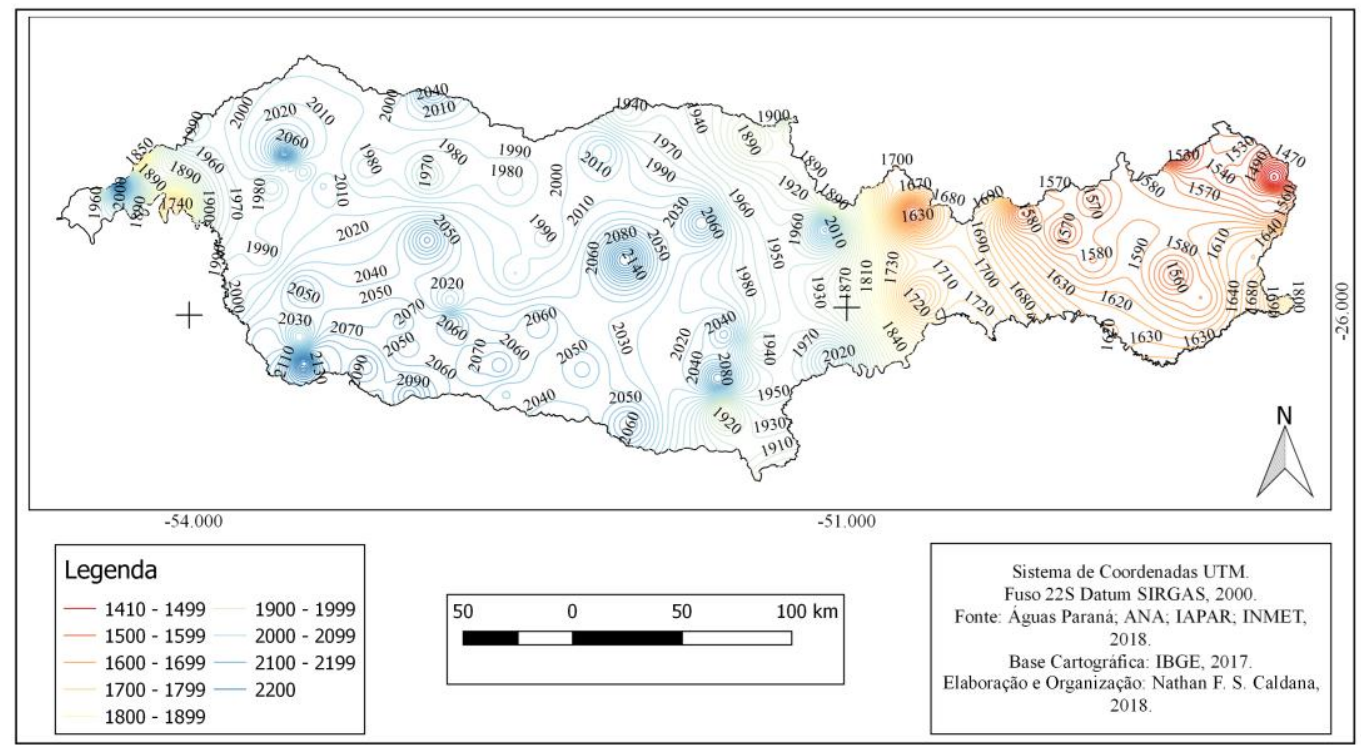

Figura 2 - Mapa da precipitação média na bacia hidrográfica do Rio Iguaçu.

Assim como no mapa das isoietas (Figura 02), é possível notar, por meio do box plot (Figura 03) grande discrepância entre os valores pluviométricos ao longo da bacia. No alto Iguaçu (estação de Quitandinha) os valores das alturas pluviométricas são inferiores em relação ao médio (estação de Guarapuava) e baixo Iguaçu (estação de Francisco Beltrão). A maior altura da precipitação anual registrada na estação de Quitandinha foi de $2140 \mathrm{~mm}$, não sendo considerado um valor discrepante na série de dados analisados, enquanto a mediana é de $1575 \mathrm{~mm}$, sendo a menor das três estações analisadas. 


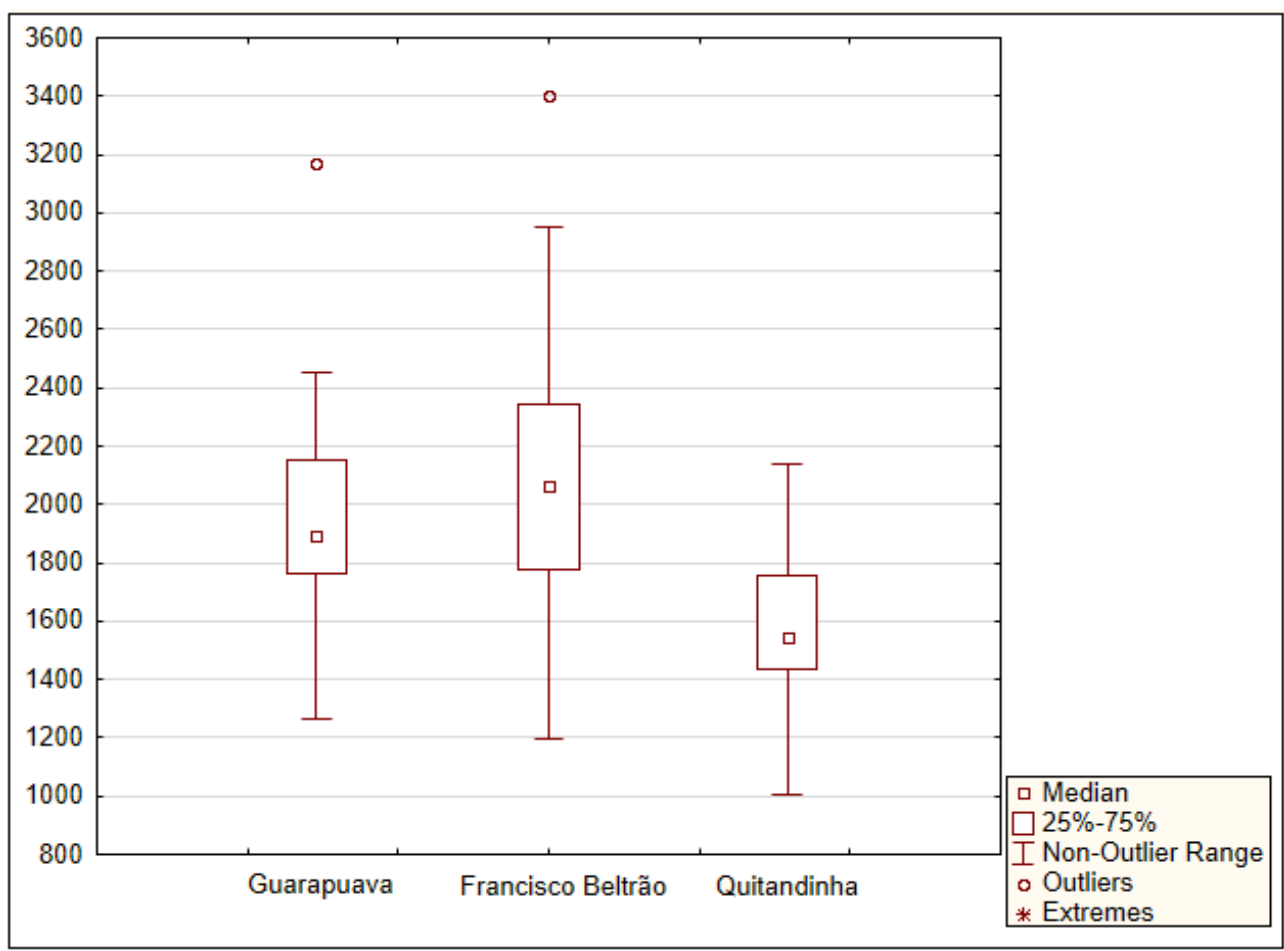

Figura 3 - Variabilidade da precipitação anual em estações da bacia hidrográfica do Rio Iguaçu.

Para as estações de Francisco Beltrão e Guarapuava, as medianas foram identificadas com alturas pluviométricas de 1870 e $2046 \mathrm{~mm}$, respectivamente. Em ambas estações foram identificados valores anômalos, correspondentes ao ano de 1983, sendo alturas de 3168.4 e $3405.3 \mathrm{~mm}$, respectivamente. Esse ano foi identificado como influência do fenômeno ENOS em anomalia de El Niño, sendo o ano mais chuvoso na bacia analisada (CALDANA e ELY, 2016).

Para a precipitação sazonal (Figura 04), os valores da caixa de quartil entre $25 \%$ e $75 \%$ de Quitandinha permanecem abaixo dos valores das demais estações. O verão apresentou a menor diferença entre as estações. Em Quitandinha foi registrada a maior altura de precipitação nesta estação com $920 \mathrm{~mm}$, assim como os menores, com alturas pluviométricas próximas aos $200 \mathrm{~mm}$. Ainda no verão, foi identificada a maior diferença entre valores dos quartis na estação de Francisco Beltrão, com aproximadamente $290 \mathrm{~mm}$. 


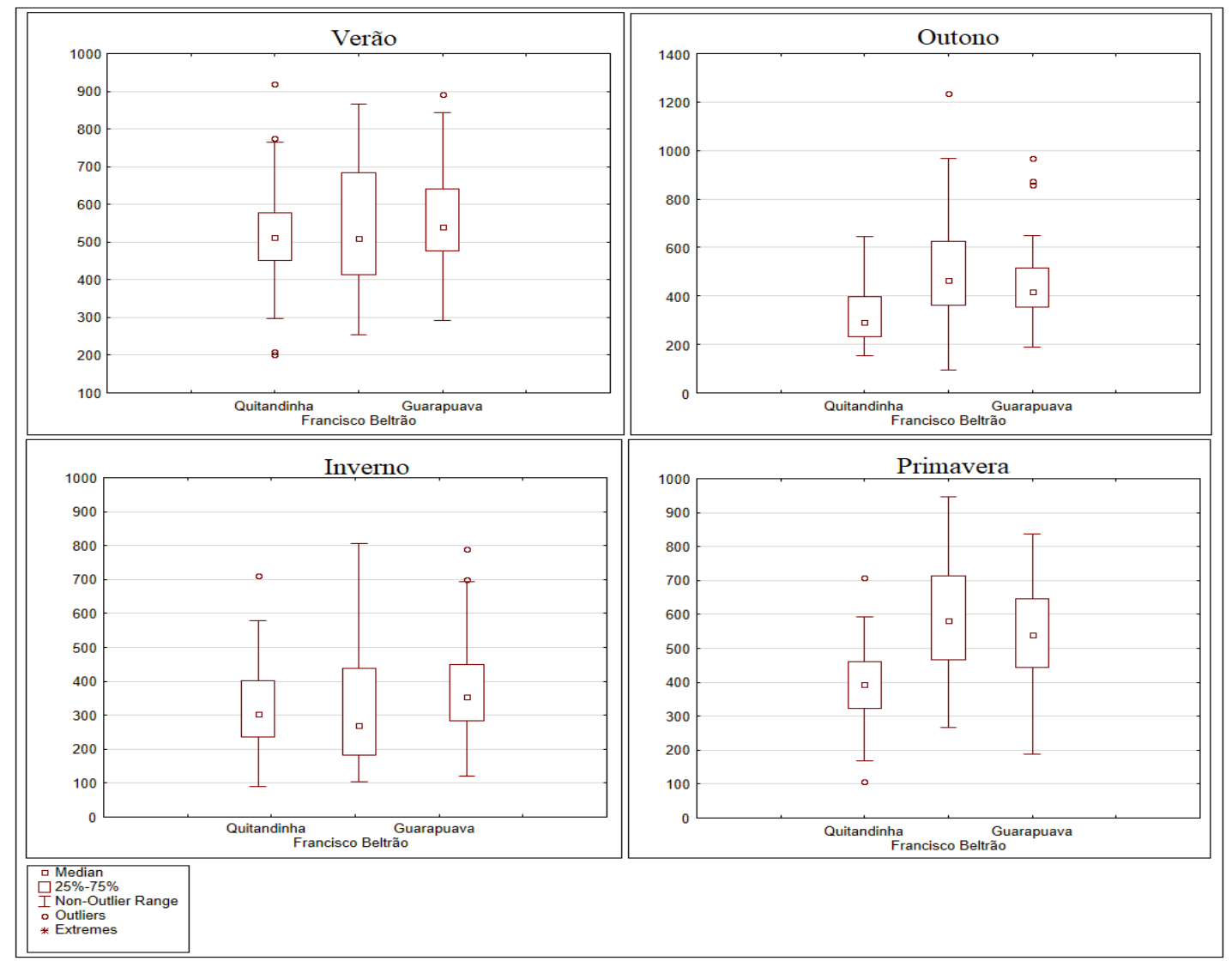

Figura 4 - Box plot da precipitação sazonal em estações da bacia hidrográfica do Rio Iguaçu.

No outono foi identificado a maior altura de precipitação em uma estação, com $1230 \mathrm{~mm}$ em Francisco Beltrão. Outros três valores foram considerados discrepantes em Guarapuava, com altura pluviométrica superior a $800 \mathrm{~mm}$.

$\mathrm{Na}$ estação de inverno foram registradas as menores alturas pluviométricas dentre as estações, porém podendo ocorrer valores extremos. Já para a primavera, observou-se aumento na precipitação em relação à estação anterior e valores discrepantes, tanto no limite superior quanto no inferior de outliers de Quitandinha.

Em todos os cenários, na estação de Francisco Beltrão identificou-se o maior intervalo entre o limite superior e inferior do box plot. Quitandinha foi a única estação a indicar valores discrepantes no limite inferior do box plot.

Para a precipitação mensal (Figura 05) observou-se a maior presença de valores discrepantes e extremos no limite superior. No limite inferior identificouse que nos meses do outono e inverno podem ocorrer períodos sem chuvas. 


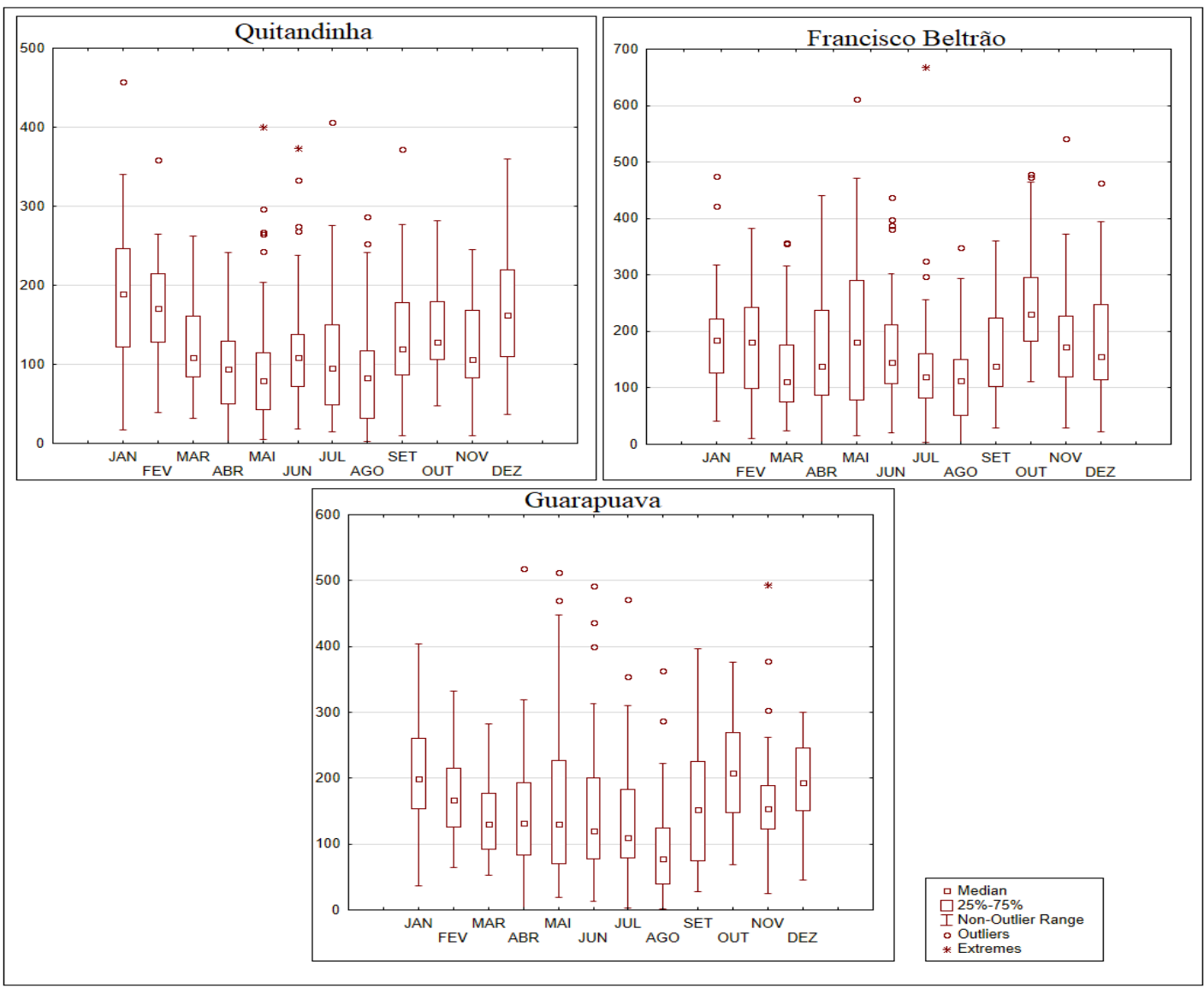

Figura 5 - Box plot da precipitação mensal em estações da bacia hidrográfica do Rio Iguaçu.

Na estação de Quitandinha observou-se no limite inferior os meses de abril e agosto sem ocorrência de precipitação. Treze valores foram identificados como discrepantes, enquanto nos meses de maio e junho foram identificados valores extremos. Nos meses de janeiro e fevereiro identificou-se a maior variabilidade entre os limites inferior e superior.

Em Francisco Beltrão, também nos meses de abril e agosto, houve incidências de meses sem precipitação. Em julho houve a maior altura pluviométrica dentre as estações analisadas, sendo registrado $680 \mathrm{~mm}$. Os meses com maior variabilidade entre o limite superior e inferior foram abril e maio. Além disso, observaram-se quinze valores como discrepantes com ocorrência na maioria dos meses.

Para a estação de Guarapuava, observaram-se doze ocorrências de valores discrepantes, principalmente nos meses de inverno. Assim como nas demais estações, nos meses de abril e agosto houve períodos sem precipitação. Apenas no mês de novembro houve a ocorrência de precipitação considerada extrema, com 492mm.

Como resposta aos impactos dos eventos extremos de chuva identificouse pelo menos uma ocorrência de alagamentos, enxurradas e inundações por 
município na bacia (Figura 06). Cabe destacar que o fato de receber assistência da Defesa Civil é evidência de que esse evento trouxe algum dano à sociedade ou ambiente.

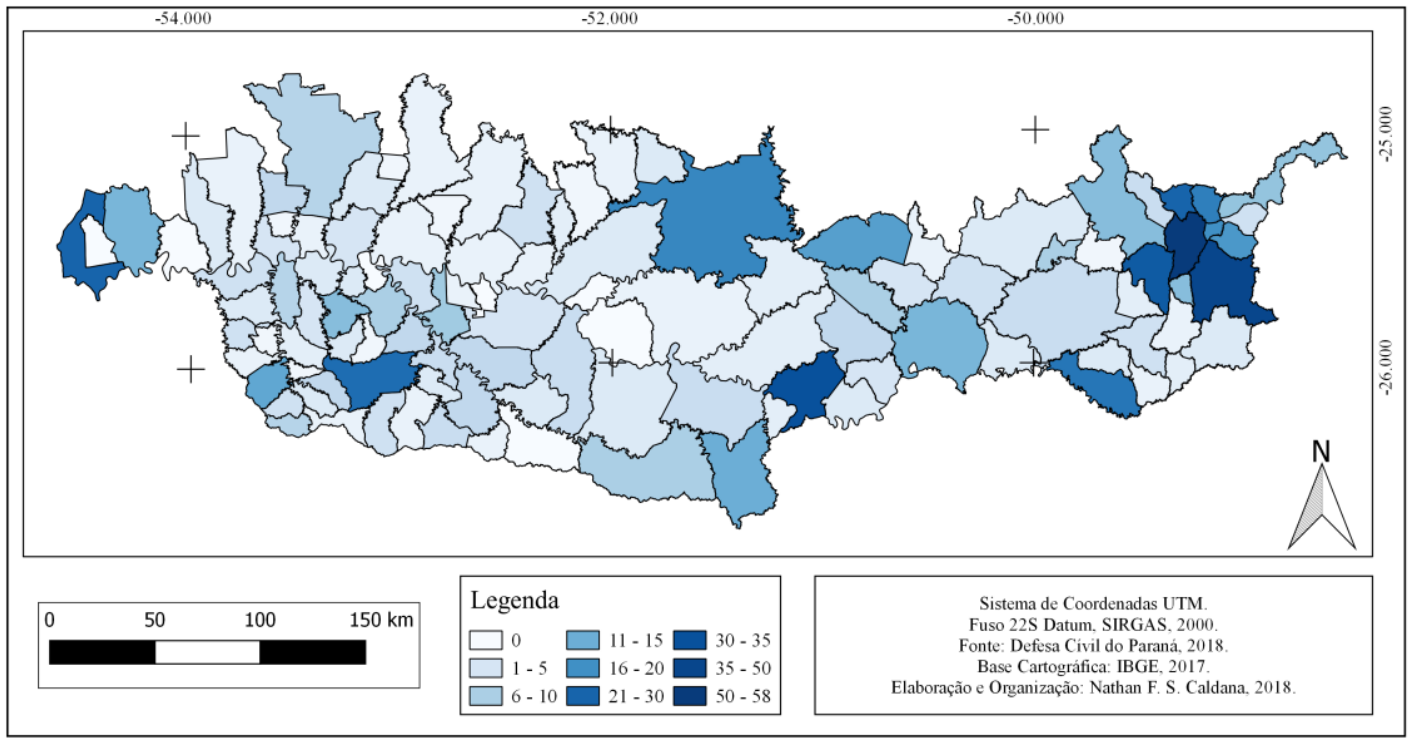

Figura 6 - Número total de ocorrências de alagamentos, enxurradas e inundações na bacia do Rio Iguaçu (2000 - 2017). Fonte dos dados: Coordenadoria Estadual de Proteção e Defesa Civil do Paraná. ORG: autores (2018)

Destacam-se com mais de 20 ocorrências os municípios União da Vitória (35), Foz do Iguaçu (27), Francisco Beltrão (25) e Guarapuava (21). Além disso, diversos municípios apresentaram números abrangentes na Região Metropolitana de Curitiba (RMC), representando um aglomerado com números significativos de ocorrências na região. Destacam-se na RMC os municípios de Curitiba (58), São José dos Pinhais (41), Araucária (28), Almirante Tamandaré (27), Rio Negro (24), Colombo (22), Pinhais (20) e Piraquara (18). No total foram 861 eventos na bacia, em média, 47 ocorrências ao ano.

Mendonça (2004, p. 148) destaca que os grandes riscos e vulnerabilidades socioambientais existente em Curitiba e na sua região metropolitana, são atribuídos a urbanização rápida e acentuada, atrelada a grande população e à "pobreza urbana, sobretudo periferias das cidades". Muitos são os exemplos de municípios com urbanização rápida e desordenada e que com isso ficam suscetíveis à ocorrência de desastres naturais, nos quais fica evidente a "interação entre impactos e riscos de inundações associados a áreas de concentração da pobreza/subabitações, que colocam em questão a veiculação de cidade exemplo de sucesso do planejamento urbano". A vulnerabilidade e os riscos destacados, abordado aqui no caso de inundações, são eminentes em toda bacia, principalmente em cidades costeiras, como União da Vitória, Rio Negro, Foz do Iguaçu, Francisco Beltrão, dentre tantas outras.

Quanto às pessoas que sofreram algum dano material ou físico (Figura 07) relacionado a alagamentos, enxurradas e inundações, destaca-se mais uma vez, a RMC, em que, Almirante Tamandaré registrou 86.061 pessoas afetadas, 
seguido de Curitiba (83.491), Pinhais (58.041) e São José dos Pinhais (34.296). Fora da RMC destacam-se União da Vitória (76.521), Irati (34.722) e Salto do Lontra (31.375); a situação deste último município é ainda mais alarmante, visto que sua população é de 13.869 habitantes (IBGE, 2018).

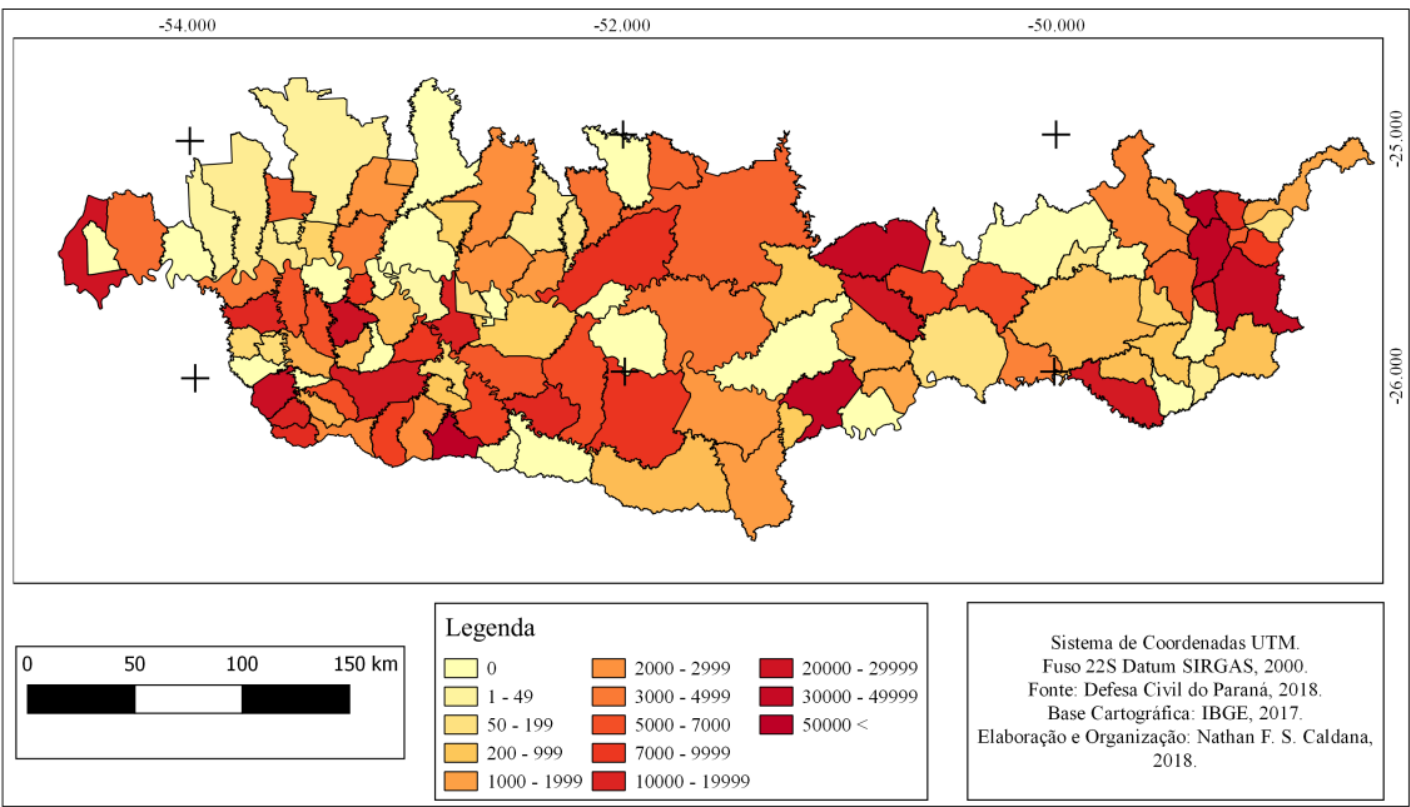

Figura 7 - Número total de pessoas afetadas por alagamentos, enxurradas e inundações na bacia do Rio Iguaçu (2000 - 2017). Fonte dos dados: Coordenadoria Estadual de Proteção e Defesa Civil do Paraná. ORG: autores (2018)

No total, foram 872.018 pessoas afetadas em 18 anos, sendo 193.056 por alagamentos, onde o município mais afetado foi Curitiba com 63.890 pessoas afetadas. Enquanto para enxurradas foram 534.550 pessoas afetadas, com ênfase para o município de Almirante Tamandaré com 85.201 casos de impacto na sociedade. E inundações com 145.112 pessoas afetadas com destaque para União da Vitória com 76.102 casos de impactos.

Ao todo foram 41 óbitos vinculados a um dos três desastres na bacia do Rio Iguaçu nos 18 anos de análise. União da Vitória foi o município que teve o maior número de registros, com sete óbitos, seguido de Guarapuava com cinco.

Vale ressaltar que esses números são registrados quando a Defesa Civil precisa realizar algum tipo de serviço para redução dos impactos dos desastres, porém para muitos casos podem não ter sido solicitado o atendimento, e assim, não sendo registrados, podendo ter valores efetivos ainda maiores de ocorrências e de impactos na sociedade.

Os problemas com alagamentos, inundações e enxurradas são frequentes em todo o mundo, e como mencionado, está presente em pelo menos $80 \%$ das cidades brasileiras. Nas últimas décadas estes eventos ganharam maior atenção pública e investimentos em infraestrutura, concentrado, principalmente, nas grandes cidades (MARCELINO, 2007; CHEN, et al. 2018). Na bacia do Rio Iguaçu os problemas causados são notórios e alarmantes, se mostraram presente em pelo menos $90 \%$ dos municípios. O planejamento dessa região 
sempre deve ser realizado com medidas que visem a melhoria da drenagem urbana, mitigando assim, esse tipo de ocorrência, e melhorando consequentemente, a qualidade ambiental e hídrica da bacia.

Trabalhos futuros se mostram necessários, com enfoque nas áreas de Meteorologia, Climatologia, Hidrologia e Planejamento Urbano, com olhar aguçado, principalmente, na escala local, buscando identificar em uma análise morfométrica os locais mais propícios, nestes municípios, a este tipo de ocorrência, para auxiliar assim, ao planejamento urbano desta região. Além disso, estudos que identifiquem as tendências pluviométricas e para os eventos extremos climáticos na região possibilitariam um planejamento em larga escala temporal.

\section{CONSIDERAÇÕES FINAIS}

Foi possível identificar grande variação regional na precipitação média da Bacia do Rio Iguaçu. Em estações do alto Iguaçu o menor valor anual foi de $1410 \mathrm{~mm}$, enquanto no baixo e médio Iguaçu os valores chegaram a $2200 \mathrm{~mm}$. Identificou-se também grande variação anual, sazonal e mensal na precipitação, com 2200mm de diferença do ano mais chuvoso para o mais seco em Francisco Beltrão. Para os meses de inverno foram identificadas as menores alturas pluviométricas, porém, com maior incidência de eventos extremos. Os únicos meses que não foi registrada precipitação na bacia foram abril e agosto, nas três estações analisadas.

Os impactos de eventos extremos de precipitação na bacia são perceptíveis por meio de alagamentos, enxurradas e inundações. No total foram 861 casos e 872.118 pessoas afetadas por um dos três desastres. A RMC é a região com maior número de ocorrências e maiores impactos na sociedade, principalmente, em Almirante Tamandaré e Curitiba. Fora da RMC, destacam-se União da Vitória e Salto do Lontra. A vulnerabilidade e os riscos dos desastres naturais causados no espaço urbano são alarmantes e devem auxiliar no planejamento e na tomada de decisão na bacia hidrográfica do Rio Iguaçu.

\section{REFERÊNCIAS}

AGOVINO, M. et al. Agriculture, climate change and sustainability: The case of EU-28. Ecological Indicators, 2018.

BERLATO, M. A.; FONTANA, D. C. El Niño e La Niña: impactos no clima, na vegetação e na agricultura do Rio Grande do Sul; aplicações de previsões climáticas na agricultura. Porto Alegre: Ed. da UFRGS, 2003. 110p.

CALDANA, N. F. S.; ELY, D. F.; Variabilidade Das Chuvas Anuais Na Bacia Hidrográfica Do Rio Iguaçu (PR). Simpósio Brasileiro de Climatologia Geográfica - XII SBCG, Goiânia, 2016.

CARAMORI, P. H. et al. Zoneamento de riscos climáticos para a cultura do café (Coffea arabica L.) no Paraná. Revista Brasileira de Agrometeorologia, Santa Maria, v. 9, n. 3, p.486-494, 2001. 
CHEN, W. et al. Urban inundation response to rainstorm patterns with a coupled hydrodynamic model: A case study in Haidian Island, China. Journal of Hydrology, v. 564, p. 1022-1035, 2018.

CONTI, J. B. Considerações sobre as mudanças climáticas globais. In: Revista do Departamento de Geografia, São Paulo, v. 16, 2005, p.70-75.

HAMMOND, M. J. et al. Urban flood impact assessment: A state-of-the-art review. Urban Water Journal, v. 12, n. 1, p. 14-29, 2015.

IBGE (Fundação Instituto Brasileiro de Geografia e Estatística), 2018. Censo Demográfico: Brasil, 2017. Rio de Janeiro: IBGE.

JAMALI, B. et al. A rapid urban flood inundation and damage assessment model. Journal of Hydrology, v. 564, p. 1085-1098, 2018.

KARIMI, V. et al. Vulnerability and Adaptation of Livestock Producers to Climate Variability and Change. Rangeland Ecology \& Management, Volume 71, Issue 2, 2017, Pages 175-184.

. et al. Climate change and agriculture: Impacts and adaptive responses in Iran. Journal of Integrative Agriculture, Volume 17, Issue 1, January 2018, Pages 1-15.

LEM, S. et al. The heuristic interpretation of box plots. Learning and Instruction, v. 26, p. $22-35,2013$.

LÓPEZ, M. S.; Analysis of the spatial distribution of scientific publications regarding vector-borne diseases related to climate variability in South America. Spatial and Spatio-temporal Epidemiology, 2018.

LUNGARSKA, A.; CHAKIR, R. Climate induced land use change in France: impacts of agricultural adaptation and climate change mitigation. Ecological Economics, v. 147, p. 134-154. May 2018,

MARCELINO, E. V.; Desastres Naturais e Geotecnologias: Conceitos Básicos. INPE, Santa Maria, 2007.

MARTINS, J.A. et al. Climatology of destructive hailstorms in Brazil. Atmospheric Research, v. 184, p. 126-138, 2017.

MENDONÇA, F. Riscos, vulnerabilidade e abordagem socioambiental urbana: uma reflexão a partir da RMC e de Curitiba. Desenvolvimento e Meio ambiente, v. $10,2004$.

MUELLER, T. G. et al. Map quality for ordinary kriging and inverse distance weighted interpolation. Soil Science Society of America Journal, v. 68, n. 6, p. 2042-2047, 2004.

PAILLER, S.; TSANEVA, M. The effects of climate variability on psychological well-being in India. World Development, v. 106, p. 15-26, 2018.

PATHMESWARAN, $C$. et al. Impact of extreme weather events on coconut productivity in three climatic zones of Sri Lanka. European Journal of Agronomy, v. 96, p. $47-53,2018$.

PINHEIRO, G. M. Variabilidade temporo-espacial da pluviosidade na Bacia do Alto Iguaçu. 2016. Tese (Doutorado). Universidade Federal do Paraná. Curitiba, 2016 
ROCHA, P. C.; SANT'ANNA NETO, J. L. Ritmo climático e dinâmica limnológica na planície fluvial do alto rio Paraná, centro-sul do Brasil. Revista Brasileira de Climatologia, v. 6, 2010.

SCHNEIDER, H.; DA SILVA, C. A. O uso do modelo box plot na identificação de anos-padrão secos, chuvosos e habituais na microrregião de Dourados, Mato Grosso do Sul. Revista do Departamento de Geografia, v. 27, p. 131-146, 2014.

SILVA, M. E. S.; SILVA, C. B. Variabilidade Climática - processos físicos e dinâmicos nos oceanos e atmosfera. Revista do Departamento de Geografia USP, Volume Especial 30 anos. São Paulo, SP, 2012. p. 372-406.

SILVESTRE, M. R. et al. Critérios estatísticos para definir anos padrão: uma contribuição à climatologia geográfica. Revista Formação, v. 2, n. 20, p. 23-53, 2013.

SOMBOONSUKE, B. et al. Farmers' perceptions of impacts of climate variability on agriculture and adaptation strategies in Songkhla. Kasetsart Journal of Social Sciences, 2018.

TANAKA, T. et al. Impact assessment of upstream flooding on extreme flood frequency analysis by incorporating a flood-inundation model for flood risk assessment. Journal of Hydrology, v. 554, p. 370-382, 2017.

WIRÉHN, L. Nordic agriculture under climate change: A systematic review of challenges, opportunities and adaptation strategies for crop production. Land Use Policy, v. 77, p. 63-74, 2018,

WOSSEN, T. et al. Impacts of climate variability and food price volatility on household income and food security of farm households in East and West Africa. Agricultural Systems, 2017 